American Journal of Applied Sciences 6 (2): 328-331, 2009

ISSN 1546-9239

(C) 2009 Science Publications

\title{
Refractive Index and Fourier Transform Infrared Spectra of Virgin Coconut Oil and Virgin Olive Oil
}

\author{
W. Mahmood Mat Yunus, Yap Wing Fen and Lim Mei Yee \\ Department of Physics, Faculty of Science \\ Universiti Putra Malaysia \\ 43400 UPM Serdang, Malaysia
}

\begin{abstract}
This study presents the refractive index and FTIR spectra of virgin coconut oil and virgin olive oil that have been measured in the wavelength range from 491.0-667.8 nm. The measurement of refractive index was carried out using a minimum deviation method while the IR transmission ranging from $600-4000 \mathrm{~cm}^{-1}$ was measured using FTIR spectrometer respectively. The measurements were done at room temperature and the dispersion equations for the studied samples were verified and the Cauchy constants were obtained by fitting the experimental data to the Cauchy formula. For both, refractive index and Cauchy constants, the value obtained are higher in virgin olive oil as compared to virgin coconut oil. A similar result for FTIR absorption spectrum was also observed where the five important peaks explaining the stretching absorption due to aldehyde $(\mathrm{C}=\mathrm{O})$ and esters $(\mathrm{C}-\mathrm{O})$, bending absorption (methylene $\left(\mathrm{CH}_{2}\right)$ and methyl $\left(\mathrm{CH}_{3}\right)$ groups and double bond absorptions $(\mathrm{C}=\mathrm{O})$ were strong in virgin olive oil.
\end{abstract}

Keywords: Refractive Index, FTIR spectra, coconut oil: olive oil.

\section{INTRODUCTION}

Refractive index plays an important role in many branches of physics, biology and chemistry. Knowledge of the refractive index of aqueous solutions and oil is of crucial importance in applications of adulteration of oils and purity. Different methods have been developed to measure the refractive index of liquids, such as the Brewster angle ${ }^{[1,2]}$, ellipsometry ${ }^{[3]}$, attenuated internal reflection $(\mathrm{ATR})^{[4,5]}$ and minimum deviation method $^{[6,7]}$. The most common and easiest method is the minimum deviation method. The theory and method have been discussed elsewhere ${ }^{[6-9]}$. Considering the beam geometry of a prism shown in Fig. 1 one can determine the minimum angle of deviation $\mathrm{D}_{\mathrm{m}}$ when the angle $\alpha$ and $\beta$ are equal. Thus the index of refraction can be obtained using the well known equation:

$$
n=\frac{\sin [(A+D) / 2]}{\sin (A / 2)}
$$

It is known that the dispersion relation of a dielectric material could be accurately fitted by Cauchy formula ${ }^{[10,11]}$.

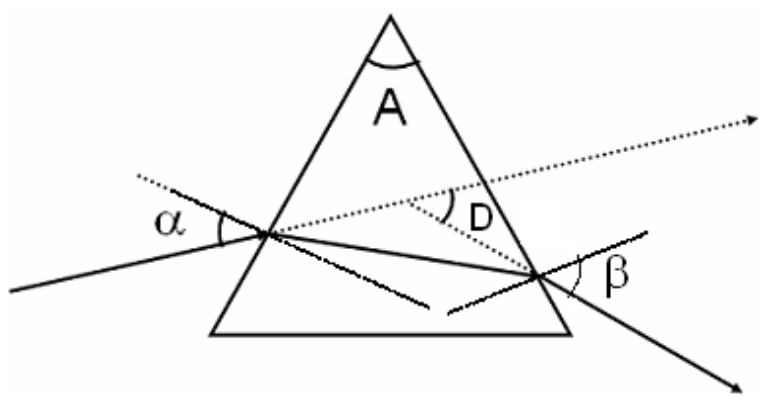

Fig. 1: Nomenclature in derivation of minimum deviation of a prism

$$
\mathrm{n}=\mathrm{A}+\frac{\mathrm{B}}{\lambda^{2}}+\frac{\mathrm{C}}{\lambda^{4}}
$$

where $\mathrm{A}, \mathrm{B}$ and $\mathrm{C}$ are constants and can be determined simultaneously by fitting the experimental values from refractive index measurement.

Virgin coconut oil is one of the best cooking oil and resistant to mutations of fatty acid chains even when used at higher temperature. It is rich in lauric acid, cupic acid and rich with nutrient that supports the body immune system. The common methods to produce

Corresponding Author: W. Mahmood Mat Yunus, Department of Physics, Faculty of Science, Universiti Putra Malaysia, 43400 UPM Serdang, Malaysia Tel: + (603)89466684 Fax: + (603)89454454 
virgin coconut oil is wet-milling methods where it does not involve the direct heating or chemical reaction. It is reported that about $92 \%$ of fatty acids in virgin coconut oil are saturated and two-thirds of these saturated fatty acids are medium-chain fatty acids. On other hand virgin olive oil is rich in monounsaturated fat and a good source of polyphenols. Due to the high monounsaturated fatty acids in virgin olive oil, it also stands out as a vegetable oil with excellent benefit for human health. This study reports the refractive index and FTIR spectra for both, virgin coconut oil and virgin olive oil, measured at room temperature $25^{\circ} \mathrm{C}$.

\section{MATERIAL AND METHOD}

The Virgin Coconut Oil (VCO) used in the present experiment was produced by natural process where the solid endosperm of mature coconut was crushed, made into viscous slurry and squeezed through a filter to obtain coconut milk which is similar to the one reported by Nevin and Rajamohan ${ }^{[12,13]}$. The oil was finally separated by solidification technique. The virgin coconut oil was kept at room temperature $\left(25^{\circ} \mathrm{C}\right)$ for 24 $\mathrm{h}$ prior to FTIR and refractive index measurements. However, the Virgin Olive Oil (VOO) sample was obtained from local superstore. The FTIR spectrometer (Perkin Elmer 1725X) was used to measure the IR transmission ranging from $600-4000 \mathrm{~cm}^{-1}$. For refractive index measurement we have employed a minimum deviation method similar to the set up as reported in our previous paper $^{[6]}$. To perform the experiment, an equilateral hallow prism as shown in Fig. 1, was fixed on a spectrometer table. A collimated beam from $\mathrm{Hg}, \mathrm{He}, \mathrm{Na}$ and $\mathrm{Cd}$ lamps were used as the light sources. The prism was then filled with oil sample and then rotated until the angle of $\alpha$ and $\beta$ become equal. The minimum deviation angle was determined from the reading of spectrometer table. By this set up we have determined the refractive index of virgin coconut oil and virgin olive oil for eight different wavelengths, i.e., 491.0, 492.1, 546.0, 577.0, 587.5, $589.3,643.8$ and $667.8 \mathrm{~nm}$. In this study the density of virgin coconut oil and virgin olive were measured using gravimetric technique and the minimum deviation set up was optimized by measuring the refractive index of distilled water at room temperature.

\section{RESULTS AND DISCUSSION}

The refractive indices of these two virgin oils measured at room temperature are shown in Fig. 2 and 3. All the data points on the graph represent three independent measurements carried out at a particular

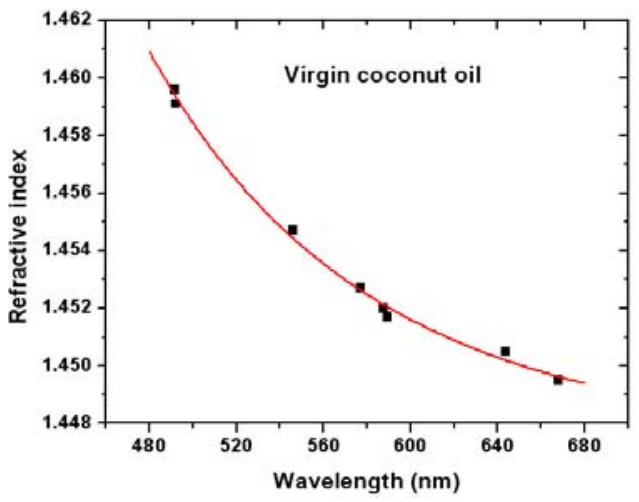

Fig. 2: Refractive index of virgin coconut oil measured at $25^{\circ} \mathrm{C}$

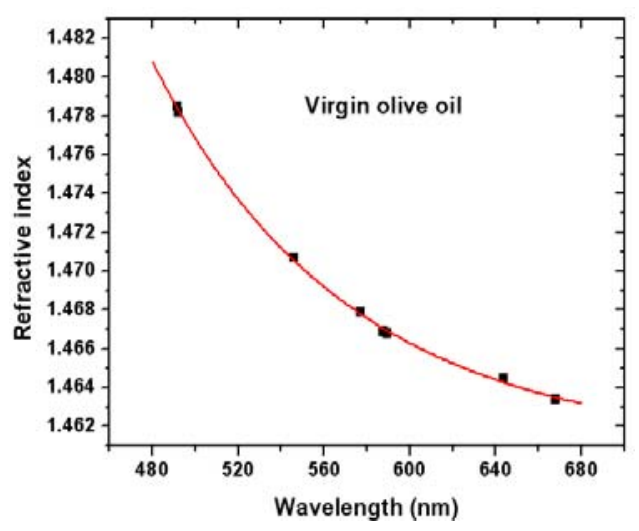

Fig. 3: Refractive index of virgin olive oil measured at $25^{\circ} \mathrm{C}$

Table 1: Density and constants A, B and C of virgin coconut oil and virgin olive oil at $25^{\circ} \mathrm{C}$

\begin{tabular}{lll}
\hline Parameter & VCO & VOO \\
\hline Density $\left(\mathrm{g} / \mathrm{cm}^{3}\right)$ & 0.8933 & 0.8639 \\
$\mathrm{~A}$ & 1.4479 & 1.4639 \\
$\mathrm{~B}$ & $-1.6789 \times 10^{3}$ & $-4.5367 \times 10^{3}$ \\
$\mathrm{C}$ & $1.0723 \times 10^{9}$ & $1.9439 \times 10^{9}$ \\
\hline
\end{tabular}

wavelength. The solid line represents the fitting line that was calculated based on Eq. 2. The density and Cauchy constants A, B and C are listed in Table 1 . The refractive index for virgin olive oil is obviously higher than the refractive index for virgin coconut oil as shown in Fig. 4.

Fig. 5 shows the FTIR spectra for virgin coconut oil and virgin olive oil. Generally the FTIR spectra show five important peaks explaining the stretching, bending and double bond absorptions of the oil samples. We observe that the absorption peaks are the same for both oil samples where the $\mathrm{C}-\mathrm{H}$ stretching absorption occurs at wavelength $2922 \mathrm{~cm}^{-1}$. This peak 
Am. J. Applied Sci., 6 (2): 328-331, 2009

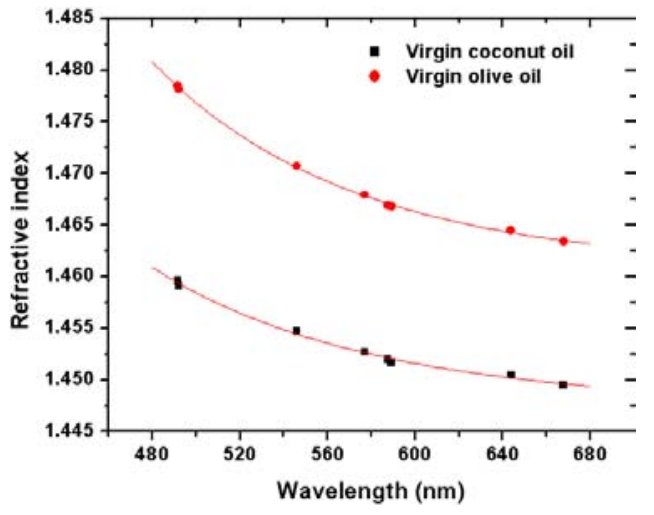

Fig. 4: Comparison of refractive index of virgin coconut oil with virgin olive oil

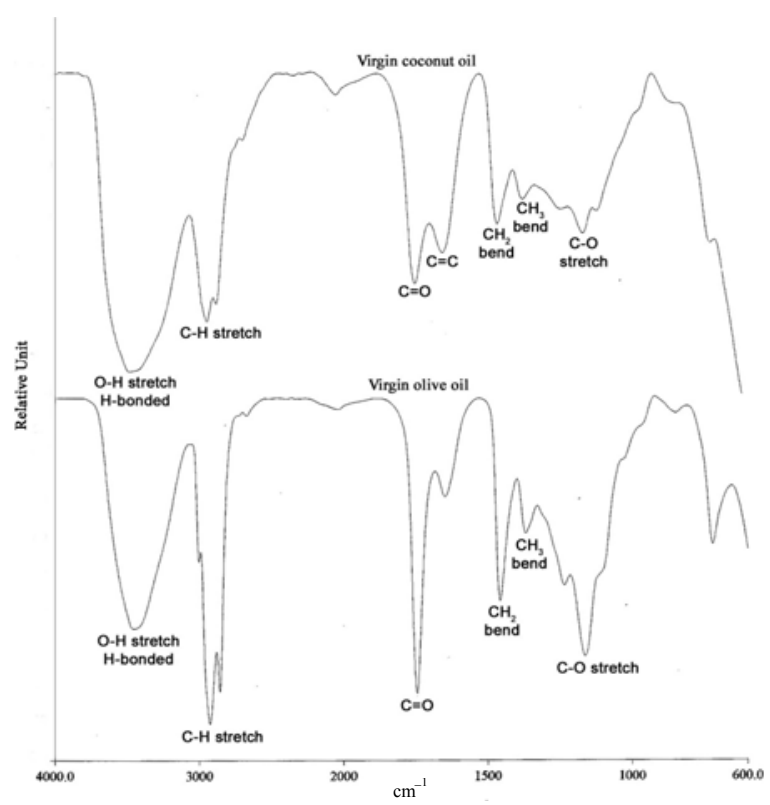

Fig. 5: Infrared spectra of (a): Virgin coconut oil and (b): Virgin olive oil

appears strong in virgin olive oil sample as shown in Fig. 2b. Two alkanes peaks which is attributed the bending absorption of methylene $\left(\mathrm{CH}_{2}\right)$ and methyl $\left(\mathrm{CH}_{3}\right)$ groups appears at 1465 and $1375 \mathrm{~cm}^{-1}$ respectively. Two peaks observed at 1740 and $1160 \mathrm{~cm}^{-1}$ are due to stretching absorption of aldehyde $(\mathrm{C}=\mathrm{O})$ and esters $(\mathrm{C}-\mathrm{O})$ respectively. All these peaks are stronger in virgin olive oil than in the virgin coconut oil. However, the stretching absorption of $(\mathrm{O}-\mathrm{H})$ at $3450 \mathrm{~cm}^{-1}$ is strong in virgin coconut oil due to the water content of the coconut oil sample. This stretching (O-H) absorption is intermolecular hydrogen bonding for water. This result describes the measured density of virgin coconut oil is slightly higher than virgin olive oil (i.e. 0.893 and $0.863 \mathrm{~g} \mathrm{~cm}^{-3}$ )

\section{CONCLUSION}

The refractive and the FTIR spectra of virgin coconut oil and virgin olive oil were successfully measured at room temperature. The refractive index was measured in the spectral range of 400-700 nm while the FTIR measurement was covered in the range of $600-4000 \mathrm{~cm}^{-1}$. All the experimental data were fitted to the Cauchy formula to obtain the Cauchy constants and it was found that the refractive index and the Cauchy constants, A, B and C of virgin olive oil are higher then the one obtained for virgin coconut oil, except for the sample density. The FTIR spectra shows that the five important peaks explaining the stretching absorption due to aldehyde $(\mathrm{C}=\mathrm{O})$ and esters $(\mathrm{C}-\mathrm{O})$, bending absorption (methylene $\left(\mathrm{CH}_{2}\right)$ and methyl $\left(\mathrm{CH}_{3}\right)$ groups) and double bond absorptions $(\mathrm{C}=\mathrm{O})$ are strong in virgin olive oil than in the virgin coconut oil samples.

\section{ACKNOWLEDGEMENT}

The authors are thankful to the Department of Physics for providing the research facilities which enable us to carry out this research successfully. The financial support from SAGA, Academic of Science, Malaysia and Ministry of Science Technology and Innovation (MOSTI) are also acknowledged.

\section{REFERENCES}

1. Schutzmann, S., M. Casalboni, F. De Materies and P. Propsposito, 2005. Refractive index measurements of thin films using both Brewster and m-line technique: A combined experimental setup. J. Non-Cryst. Solids, 351: 1814-1818. DOI: 10.1016/j.jnoncrysol.2005.04.022.

2. Una-Moreno, D., E. De. La Rosa-Cruz, F.J. Cuevas, L.E. Regalado, P. Salas, R. Rodriguez, V.M. Castano, S. Schutzmann, M. Casalboni, F. De Materies and P. Propsposito, 2002. Refractive index measurement of pure and $\mathrm{Er}^{3+}$ doped $\mathrm{ZrO}^{2}-\mathrm{SiO}^{2}$ sol gel film by using the Brewster angle technique. Opt. Mater., 19: 275-281. Doi: 10.1016/S09253467(01)00190-2 .

3. Azzam, R.M.A. and N.M. Bashara, 1977. Ellipsometry and Polarized Light. North-Holland Amsterdam, pp: 1-10. DOI: 10.1016/00303992(78)90108-1. 
4. Raty, J., E. Keraneny and K.E. Peiponenz, 1998. The complex refractive index measurement of liquids by a novel reflectometer apparatus for the UV-visible spectral range. Meas. Sci. Technol., 9: 95-99. DOI: 10.1088/0957-0233/9/1/012.

5. Jin, Y.L., J.Y. Chen, L. Xu and P.N. Wang, 2006. Refractive index measurement for biomaterial samples by total internal reflection. Phys. Med. Biol., 51: N371-N379. DOI: 10.1088/00319155/51/20/N02.

6. Yunus, M.M.W. and A.R. Azizan, 1988. Refractive index of solution at high concentrations, Appl. Opt., 27: 3341-3343. URI: ao-27-16-3341.

7. Daimon, M. and A. Masumura, 2007. Measurement of the refractive index of distilled water from the near-infrared region to the ultraviolet region. Appl. Opt. 20, 46: 3811-3820. DOI: $10.1364 / A O .46 .003811 . U R I=a 0-46-18-3811$

8. Jenkin, D. D, 1982. Refractive index of solution. Phys. Educ. 17: 82-83. DOI: 10.1088/00319120/17/2/413.

9. Cariou, J. M., J. Dugas, L. Martin and P. Michel, 1986. Refractive index variation with temperature of PMMA and Polycarbonate. Appl. Opt., 25: 334-336. URI: ao-25-3-334.
10. Chandra, B.P. and C. Bhaiya, 1983. A simple, accurate alternative to minimum deviation method of determining the refractive index of liquids. Am. J. Phys., 51: 160-161. Doi: 10.1119/1.13314.

11. Khodier, S.A., 2002. Refractive index of standard oils as a function of wavelength and temperature. Opt. Laser Technol., 34: 125-128. Doi: 10.1016/ S0030-3992(01)00101-3.

12. Nevin, K.G. and T. Rajamohan, 2004. Beneficial effects of virgin coconut oil on lipid parameters and in vitro LDL oxidation. Clin. Biochem., 37: 830-835. Doi: 10.1016/j.clinbiochem.2004. 04.010 .

13. Nevin, K.G. and T. Rajamohan, 2008. Influence of virgin coconut oil on blood coagulation factors, lipid levels and HDL oxidation in cholesterol fed Sprague-Dawley rats. e-SPEN, Eur. e-J Clin. Nutr. Metab., 3: e1-e8. Doi: 10.1016/j.eclnm. 2007.09.003. 